\title{
Variation in physical measurements and macronutrient quality of diet of care assistants and nurses working alternating shift patterns in comparison to day workers
}

\author{
Louise Mills, Jessica Hindley and F. Amirabdollahian \\ School of Health Sciences, Liverpool Hope University, Hope Park, Liverpool, L16 9JD
}

Research on the influence of shift work on weight gain and contribution of macronutrients to overall energy intake of care assistants and nurses is limited and previous studies have produced indistinct conclusions ${ }^{(1,2)}$. Our earlier work demonstrated that the disruption of circadian rhythms associated with shift work might have adverse effects on energy and macronutrient intake of alternating shift working health care professionals ${ }^{(3)}$. The current study was conducted to add to this finding and its aim was to investigate the anthropometric measures and percentage contribution of macronutrients to overall energy intake of care assistants and nurses working alternating shift patterns in comparison to regular day workers.

After obtaining ethical approval, 80 female care assistants and nurses (including 40 alternating shift workers and 40 day workers) aged 19-64 years were recruited with help of two gatekeepers. The anthropometric measures including weight and height were collected using standardised techniques. Energy intake was measured via 24-hour diet recall previously validated in large scale research. For alternating shift workers, the dietary recall was collected in completion of a night work shift. Normal distribution was investigated using the Shapiro-Wilk test of normality and because the main variables were not normally distributed $(P<0 \cdot 05)$, they were investigated using the nonparametric Mann Whitney U Test.

The median weight, height and BMI of shift workers were significantly higher than day workers (Table 1). This finding was consistent with previous finding demonstrating significantly higher energy and macronutrient intake of shift workers in comparison with day workers ${ }^{(3)}$.

Table 1. The detail of anthropometric measures and percentage contribution of macronutrients to overall energy intake of shift and day worker health care professionals;

\begin{tabular}{|c|c|c|c|c|c|c|}
\hline \multirow[b]{3}{*}{ Energy and Macronutrients } & \multicolumn{3}{|c|}{ Shift Workers $(N=40)$} & \multicolumn{3}{|c|}{ Day Workers $(N=40)$} \\
\hline & \multirow[b]{2}{*}{ Median } & \multicolumn{2}{|c|}{ Quartiles } & \multirow[b]{2}{*}{ Median } & \multicolumn{2}{|c|}{ Quartiles } \\
\hline & & $\mathrm{P} 25$ & P75 & & $\mathrm{P} 25$ & P75 \\
\hline Weight $(\mathrm{kg})$ & $68 \cdot 2 *$ & $63 \cdot 5$ & $77 \cdot 8$ & $66 \cdot 7$ & $61 \cdot 8$ & $69 \cdot 7$ \\
\hline Height (m) & $1.62 * *$ & 1.60 & 1.67 & 1.67 & $1 \cdot 60$ & 1.70 \\
\hline BMI $\left(\mathrm{kg} / \mathrm{m}^{2}\right)$ & $26 \cdot 4 * * *$ & $25 \cdot 4$ & $28 \cdot 6$ & $24 \cdot 3$ & $22 \cdot 6$ & 25.7 \\
\hline$\%$ contribution of Carbohydrate to energy intake & $45 \cdot 3$ & $42 \cdot 0$ & $54 \cdot 6$ & $46 \cdot 8$ & $40 \cdot 5$ & $54 \cdot 9$ \\
\hline$\%$ contribution of NMES to energy intake & $20 \cdot 2$ & $17 \cdot 6$ & $30 \cdot 1$ & $20 \cdot 3$ & $17 \cdot 6$ & $29 \cdot 0$ \\
\hline$\%$ contribution of Fat to energy intake & $34 \cdot 9^{*}$ & $29 \cdot 6$ & $37 \cdot 4$ & $30 \cdot 7$ & $27 \cdot 8$ & $33 \cdot 7$ \\
\hline$\%$ contribution of Saturated fat to energy intake & $11 \cdot 1$ & $8 \cdot 4$ & $15 \cdot 6$ & $9 \cdot 8$ & $8 \cdot 2$ & $13 \cdot 1$ \\
\hline$\%$ contribution of Protein to energy intake & 11.9 & $9 \cdot 8$ & $14 \cdot 7$ & $12 \cdot 0$ & $9 \cdot 2$ & $15 \cdot 3$ \\
\hline
\end{tabular}

${ }^{*} p<0 \cdot 05, * * P<0 \cdot 01, * * * P<0 \cdot 001$

Although there was no significant variation in consumption of Non-Milk Extrinsic Sugars (NMES) by shift work pattern, the median consumption was substantially above the recommended maximum 10 per cent of total dietary energy regardless of the pattern of work. The median percentage contribution of fat to total dietary energy intake of alternating shift workers was statistically higher than day workers and above the Dietary Reference Values for fat ${ }^{(4)}$. With regard to main sources of fat and sugar intake, sweet and savoury pastries (e.g. sausage rolls), crisps, pot noodles, Pasta 'n' Sauces, cakes, muffins, chocolate and takeaway convenient foods (e.g. pizza) ordered from nearby outlets were common especially among care assistants and nurses working alternating shift patterns.

Health care professionals working in alternating shift patters are potentially at risk of positive energy balance and may benefit from supporting organisational strategies to facilitate healthy eating and lifestyle.

1. Zhao I, Bogossian F, Song S, Turner C (2011) J Occup Environ Med, 53, 153-8.

2. De Assis MAA, Kupek E, Nahas MV, Bellisle F (2003) Appetite, 40, 175-183.

3. Hindley J, Mills L, Amirabdollahian F (2014) Proc Nutr Soc (in press)

4. Department of Health (1991) Dietary Reference Values for Food Energy and Nutrients for the United Kingdom. London. HMSO. 